\title{
GESTÃO EDUCACIONAL PÚBLICA: PAPEL DOS GESTORES NA CONSTRUÇÃO DO PROJETO EDUCATIVO
}

\author{
PUBLIC EDUCATIONAL MANAGEMENT: ROLE OF THE MANAGERS IN THE \\ CONSTRUCTION OF THE EDUCATIONAL PROJECT
}

\section{GESTIÓN EDUCATIVA PÚBLICA: PAPEL DE LOS DIRECTORES EN LA CONSTRUCCIÓN DEL PROYECTO EDUCATIVO}

\author{
Elke Luanne da Silva Xavier ${ }^{1}$ \\ Edite Maria Sudbrack2 \\ Silvia Regina de Oliveira ${ }^{3}$
}

\begin{abstract}
RESUMO
Este artigo objetivou refletir sobre a gestão pública nas escolas e o papel dos gestores na construção do projeto educativo. Discorreu-se a respeito da gestão participativa, considerando também a gestão pública e a educação. A educação, para estes escritos, é compreendida como direito fundamental da pessoa humana, por ser condição necessária à vida na sociedade. Trata-se de uma pesquisa bibliográfica, qualitativa e exploratória, que contou com a contribuição de muitos estudiosos da área como Aranha (1996); Libâneo (2004); Nascimento (2019); Souza (2006, 2016, 2017); Chizzotti (2006) entre outros nomes relevantes para a pesquisa. A gestão participativa é responsável por tornar a escola um ambiente mais interessante para os alunos, é necessário que os gestores e a comunidade tomem consciência da importância da sua participação para melhorar o processo educacional. 0 processo educativo é a base para a construção de um país mais democrático, uma vez que a adoção de mecanismos de gestão democrática da educação possibilita a construção de práticas e vivências democráticas nas escolas
\end{abstract}

PALAVRAS-CHAVE: Gestão democrática. Participação. Políticas educacionais.

\section{ABSTRACT}

This work aimed to research about the public management in schools and the role of the managers in the construction of the educational project. The participatory management was discussed, also considering

\footnotetext{
1 Possui graduação em Ciências Contábeis pela Universidade de Cuiabá (2012). Técnico em Secretaria Escolar pelo Instituto Federal de Mato Grosso (2014). Especialização em Gestão e Organização de Escola pela Universidade Norte do Paraná (2015). Mestranda em Educação pela Universidade Regional Integrada do Alto Uruguai e das Missões - URI (2019). Atualmente é Técnico Administrativo Educacional Secretaria de Estado de Educação do Estado do Mato Grosso. Tem experiência na área de Educação, com ênfase em Educação. E-mail: elkeluanne@hotmail.com

2 Pós-Doutorado em Educação (2020) Universidade de Aveiro/Portugal; Pós-Doutorado em Educação (2016) UFRGS (Universidade Federal do Rio Grande do Sul); Doutora (2002) e Mestre em Educação (1995) pela UFRGS. Possui Graduação em Pedagogia pela Universidade Federal de Santa Maria (1975). Atualmente é Pró-reitora de Ensino da URI. Atuou como Diretora Acadêmica (2002-2010) e como Chefe do Departamento de Ciências Humanas (2010-2014), é docente do PPGEDU (Programa de PósGraduação Stricto Sensu em Educação Mestrado e Doutorado) e professora da Universidade Regional Integrada do Alto Uruguai e das Missões. E-mail: sudbrack@uri.edu.br

3 Possui licenciatura e bacharelado em história pela Universidade Federal de Mato Grosso - UFMT (2002); Bacharelado em Serviço Social pela Fundação Universidade do Tocantins -UNITINS (2012); Com três pós-graduações a nível de especialização: Mídias em Educação (UFMT), Gestão Pública (UNEMAT) e Desenvolvimento Regional (UFMT), está cursando Mestrado em Educação pelo Programa de Pós-graduação em Educação da Universidade Regional Integrada do Alto Uruguai e da Missões (URI) Câmpus de Frederico Westphalen/RS. E-mail:097465@uri.edu.br
}

Revista de Ciências Humanas, Frederico Westphalen - RS, v. 22, n.1, p. 88-100, jan./abr. 2021.

\begin{tabular}{l|l} 
Recebido em: 23/05/2021 & Aceito em: 02/06/2021
\end{tabular}


the public management and the education. The education, for these writings, is understood as a fundamental right of the human person, as it is a necessary condition for life in the society. This is a bibliographic, qualitative and exploratory research, which had the contribution of many scholars in the area, such as Aranha (1996); Libâneo (2004); Nascimento (2019); Souza (2006, 2016, and 2017); Chizzotti (2006) among other names relevant to the research. The participatory management is responsible for turning the school into a more interesting environment for the students, it is necessary that the managers and the community become aware of the importance of their participation to improve the educational process. The educational process is the basis for the construction of a more democratic country, since the adoption of democratic educational management mechanisms enables the construction of democratic practices and experiences in the schools.

KEYWORDS: Public Management. Participation. Educational Policies.

\section{RESUMEN}

Este artículo tuvo como objetivo investigar sobre la gestión pública en las escuelas y el papel de los administradores en la construcción del proyecto educativo. Se discutió la gestión participativa, considerando también la gestión pública y la educación. La educación, para estos escritos, se entiende como un derecho fundamental de la persona humana, ya que es una condición necesaria para la vida en sociedad. Se trata de una investigación bibliográfica cualitativa y exploratoria, que contó con el aporte de muchos estudiosos en el campo como Aranha (1996); Libâneo (2004); Nascimento (2019); Souza (2006, 2016, 2017); Chizzotti (2006) entre otros nombres relevantes para la búsqueda. La gestión participativa se encarga de hacer de la escuela un entorno más interesante para los estudiantes, es necesario que los gestores y la comunidad tomen conciencia de la importancia de su participación para mejorar el proceso educativo. El proceso educativo es la base para la construcción de un país más democrático, ya que la adopción de mecanismos de gestión de la educación democrática permite la construcción de prácticas y experiencias democráticas en las escuelas.

PALABRAS CLAVE: Gestión Pública. Participación. Políticas educativas.

\section{CONSIDERAÇÕES INICIAIS}

Este ensaio se propõe a debater o preceito da gestão educacional, sob a perspectiva do papel dos gestores na consecução da participação dos sujeitos que interagem na escola. Sob este prisma, defende-se a gestão democrática, preceito garantido na Lei de Diretrizes da Educação (LDB), e, anteriormente na Constituição Federal de 1988. Iniciamos este percurso tecendo a reflexão acerca da importância da educação enquanto direito de todos e de cada um. Tal direito é, por vezes, secundarizado pelas políticas educacionais, exige vigilância dos educadores e dos pesquisadores para não vermos subtraídas as conquistas duramente conseguidas. Assim, a educação pode e deve ser o mais importante espaço de formação cidadã (BRASIL, 2004).

A educação, compreendida como direito fundamental da pessoa humana, por ser condição necessária à vida na sociedade, vai além da escolarização e ocorre em diferentes espaços, pois incorpora o sentido de formação humana que, por ser humana, é ininterrupta e inacabada; por ser formação, é continuada, ou seja, se faz por toda a vida, o que pressupõe aprendizados de forma continuada ao longo de toda a vida, entendendo que, enquanto há vida, há possibilidade de formação/transformação (ASSMANN, 2007). No caso deste estudo, 
referimos de forma mais analítica ao espaço intencional da educação, que se dá na escola, em particular.

Segundo Monteiro e Arruda (2011) o direito do ser humano à educação, na prática, não é tão simples, o caminho, a forma como o educando chega à escola e a sua permanência na escola influencia no processo de aprendizagem. Muitos casos de evasão escolar estão relacionados a fatores socioeconômicos. Para muitos alunos, devido à sua origem social, a única fonte de informação é a escola. A família não Ihes possibilita valores culturais, boa alimentação, habilidades, códigos linguísticos, que Ihes propiciem um padrão intelectual comum ao meio social em que vivem, assim, a origem social influencia no tempo de permanência na escola. Geralmente, a repetência é inevitável e a autoconfiança é abalada.

Em um sistema educacional excludente e seletivo, são muitas as faces da desigualdade, seja de acesso, permanência ou de aprendizagem, bem como, estrutura física e materiais disponíveis nos estabelecimentos escolares. Sem mencionar as diferenças de formação inicial e continuada dos docentes.

Dessa forma, no interior da escola deve ocorrer a aquisição de um conjunto de informações, habilidades e valores que, evidentemente, não são adquiridos somente com a atuação do professor em sala de aula, mas sim em todos os ambientes da escola. Em todos eles deve ocorrer a comunicação, interação e vivência coletiva dos alunos com os trabalhadores em educação não docentes, denominados de funcionários de escola (BRASIL, 2004).

Este coletivo que habita a escola tem a prerrogativa de participar do Projeto Educativo ou Projeto Pedagógico Educativo, direito assegurado pela LDB, Lei 9394/1996, onde se lê:

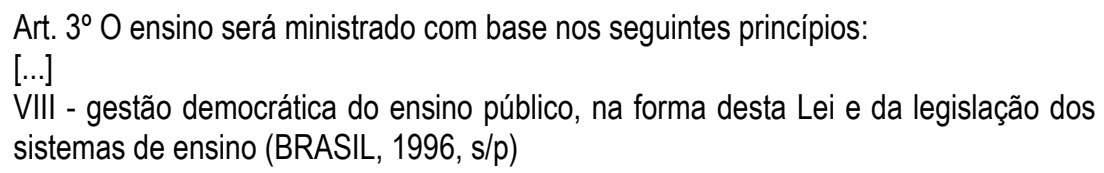

Percebe-se que a referida lei assinala que a gestão democrática do ensino público é uma forma de conceder autonomia às unidades federadas, que assim poderão definir as formas de operacionalização da gestão, contando com o conhecimento dos profissionais da educação e de toda a comunidade escolar. E na Constituição Federal art. 206:

\section{Art. 206. 0 ensino será ministrado com base nos seguintes princípios: $[\ldots]$$$
\text { VI - gestão democrática do ensino público, na forma da lei (BRASIL, 1988, s/p) }
$$

A legislação pressupõe que a educação é processo social que envolve colaboração e participação da comunidade escolar e mais ampla, como por exemplo, através dos Conselhos 
Escolares. Por meio desta articulação, enseja-se a qualidade da educação, eis que a gestão democrática contribui para aproximar a escola de seu entorno, em um ambiente de abertura e diálogo.

A abordagem deste ensaio, além de mencionar a metodologia, remete à escola e à aprendizagem, à gestão pública e à gestão participativa, enquanto elementos inseridos na concepção de gestão democrática.

\section{METODOLOGIA}

Neste ensaio, o desenho metodológico, baseia-se em uma pesquisa qualitativa, quanto aos meios, trata-se de uma pesquisa bibliográfica. Para o Chizzotti (2006), a pesquisa qualitativa é um campo transdisciplinar que engloba ciências humanas e sociais, trata-se de um método que busca encontrar o sentido do fenômeno estudado, procura seu significado para o grupo em questão. Esse tipo de pesquisa implica em partilha com pessoas, fatos e locais, visando encontrar os significados visíveis e latentes que apenas são percebíveis através de um olhar sensível (CHIZZOTTI, 2006).

Para Ribeiro e Zanirato (2007), a pesquisa qualitativa constitui uma excelente forma de investigação quando o pesquisador tem como escopo a análise de fenômenos que carregam componentes subjetivos, uma vez que não há como precisá-los quantitativamente.

Já a pesquisa bibliográfica, segundo Treinta; et al. (2012), é um processo que precisa ser contínuo, cabe ao pesquisador se questionar se todos os artigos científicos e materiais possíveis foram analisados, é preciso atenção às novas possibilidades, pois deve-se buscar sempre uma pesquisa consistente. Os autores ainda assinalam que, dada a gama de informações disponíveis, o pesquisador precisa ser criterioso e estabelecer estratégias que possibilitem a identificação dos principais trabalhos sobre o tema em pauta.

O item a seguir refere a tarefa mais genuína da educação escolar, que é a aprendizagem de todas as crianças

\section{A ESCOLA E A APRENDIZAGEM}

De acordo com Aranha (1996), é com base nas relações que instituem entre si que os indivíduos criam padrões de comportamentos, instituições e saberes, cujo aprimoramento é realizado pelas gerações seguintes, o que Ihes permite assimilar e transformar os modelos estimados em uma determinada cultura. $E$, nesse sentido, é a educação que mantém viva a 
memória dos seres humanos e lhes dá condições para sua sobrevivência, dessa forma, ela se molda como instituição mediadora que torna possível a harmonia entre os homens e a sociedade.

Guerra (2000), apresenta três ideias básicas que perfazem a definição de escola como organização que aprende. A escola que aprende é sem dúvida a escola capaz de inovar-se, de forma que os três atributos que a definem são também as condições para a ação inovadora. As três condições para que a escola se converta em agência inovadora são, inicialmente, constituirse como comunidade, o que se refere a um conjunto de pessoas com um projeto comum, que compartilham identidade e vínculos, gerados e mantidos por finalidades comuns e gestão democrática.

A segunda é assumir como foco central, nesta comunidade, a aprendizagem, ela se refere não só à aquisição de novos conceitos ou ideias, mas também à assimilação de procedimentos, habilidades, destrezas encaminhadas à compreensão de mundo e à sua melhora, iniciado pelo universo de atuação de cada um. Não se trata apenas da aprendizagem dos alunos, mas da aprendizagem de todos os sujeitos que atuam nas diferentes instâncias do processo educativo (GUERRA, 2000).

A terceira exige que esta comunidade de aprendizagem seja crítica, faz referência à capacidade reflexiva e discriminadora que permite desvelar a realidade e o conhecimento que a representa. Assimila, transmite sim, mas, sobretudo, analisa, elabora e toma posição, não se submete "a tirania do significado imposto" (GUERRA, 2000 apud RUDDUCK, 1988, p. 31). Assim, percebe-se que quando o docente busca por uma resposta certa e única, ele certamente está focado no material didático pronto, faltando para ele a autonomia de pensamento.

Com as sucessivas transformações e com a disseminação da tecnologia da informação de forma rápida, mais do que qualquer outra coisa, constituir-se-á como determinante a capacidade de aprender de cada indivíduo. "A questão hoje é menos possuir a informação do que saber encontrá-la, selecioná-la, utilizá-la de forma apropriada, saber sua veracidade, sua credibilidade, a que interesses está servindo" (LIBÂNEO, 2004, p. 47). As instituições escolares precisarão estar qualificadas para auxiliar nesta formação, visando a preparar os sujeitos para a sociedade da aprendizagem.

Os índices de escolaridade, assim como o número de anos que um aluno permanece na escola, têm aumentado significativamente. Isto poderia nos levar a concluir que está havendo maior aprendizagem e que os alunos estão se qualificando cada vez mais, no entanto isto não ocorre dentro de uma sistemática tão natural. "Mais educação escolar nem sempre corresponde 
a uma aprendizagem melhor" (HARGREAVES, 2004, p. 31). Tanto os docentes quanto as escolas precisam participar deste processo e ajudar a estruturar a aprendizagem do aluno, são necessários professores comprometidos e engajados no acompanhamento e na análise da aprendizagem.

Em diferentes momentos da história da educação encontramos questionamentos sobre a aprendizagem, sobre a origem do conhecimento. Diferentes teorias surgiram versando sobre esta problemática. De acordo com Grossi (2004), sabemos hoje que a aprendizagem é uma construção, que os conhecimentos nem estão prontos dentro de nós e nem vêm prontos de fora. Eles resultam do encontro de polos bem nítidos como "de uma inteligência ativa de quem quer compreender o mundo; da realidade que ao nosso redor; da influência forte dos grupos humanos com os quais temos contato" (GROSSI, 2004, p. 24). Esta atitude progride e projeta o aprender como resultado do esforço do aprendente em interação com o meio e com outros indivíduos.

\section{GESTÃo PÚBLICA E A EDUCAÇÃO}

O debate sobre a nova gestão pública da educação no Brasil tem se concentrado em um movimento contraditório entre defensores da incorporação de princípios do setor privado no setor público, vinculados a instituições do terceiro setor e aqueles que desenvolvem uma crítica ao modelo gerencial implantado na organização e na gestão dos sistemas educacionais. Sabemos que a inspiração teórica da nova gestão pública ressalta as virtudes dos serviços realizados por empresas e a sua centralidade para o alcance da eficiência e melhoria da oferta dos serviços públicos, na medida em que recorre aos princípios do mercado (SOUZA; CABRAL NETO, 2017).

A gestão da escola pública e a necessidade de autonomia ganha força nos anos de 1980, momento em que se lutava pela democratização da sociedade. Nessas frentes de lutas, a educação conquista o direito de decidir suas metas e propósitos, com a participação de vários segmentos da comunidade escolar. Bandeiras como descentralização, autonomia, financiamento, participação compõe cenário do final dos anos de 1980. Mas eis que a influência dos organismos internacionais, na esteira da globalização neoliberal tornada hegemônica muda o rumo das políticas educacionais.

Assim, a partir da década de 1990 um novo modelo de gestão pública foi introduzido no Brasil, resultado de um processo de alastramento das ideias neoliberais pelo mundo, sendo explicado pelo intuito de melhoria da governança social ligada à eficácia da gestão. 
novo Estado. Este novo Estado será o resultado de profundas reformas. Estas reformas habilitarão o Estado a desempenhar as funções que 0 mercado não é capaz de desempenhar. $O$ objetivo é construir um Estado que responda às necessidades de seus cidadãos (BRESSER-PEREIRA, 1998, p. 36).

Esses novos ideais de educação são resultado das mudanças ocorridas no campo econômico, político e cultural durante no final século XIX e início do século XX, com a ascensão da sociedade industrial europeia, que, aos poucos, foi tomando dimensões maiores, espalhandose pelos demais continentes. Essa nova configuração social demandava também uma nova forma de compreender a educação. O desenvolvimento científico no campo da psicologia e medicina, principalmente, forneceram as bases para o desenvolvimento da racionalidade pedagógica, capaz de combinar características individuais e exigências sociais, respondendo as demandas do sistema (DRABACH, 2011).

Diante dessa nova realidade, os sistemas escolares sofreram pressão para que a sua evolução cumprisse com as funções outorgadas pela economia e pela sociedade, portando uma dimensão mais heterogênea das políticas educacionais mais recentes. As bases desse novo processo têm origem a partir da incorporação do referencial da nova gestão pública (NGP) na gestão dos sistemas educacionais. A NGP é heterogênea e resultante de novas maneiras de pensar a organização, partindo de princípios e práticas da administração privada, preconizados por organismos internacionais, de acordo com as experiências de países anglo-saxões (OLIVEIRA, 2015).

Conforme argumenta Souza (2016), a globalização neoliberal provocou mudanças nas relações entre Estado e sociedade, bem como na valorização das prerrogativas de mercado assumidas pela administração pública, tratando, dentre a diversidade de temas, a nova gestão pública como gerencialismo. Para compreender o que esses fenômenos significam e como foram incorporados na realidade, é preciso tomar como referência a dinâmica histórica e as formas que o gerencialismo assume em diferentes contextos.

Para Souza e Cabral Neto (2017, p. 624) a "NGP é heterogênea e resultante de novas maneiras de pensar a organização, partindo de princípios e práticas da administração privada preconizados por organismos internacionais", os autores ainda assinalam que entre as características da NGP está a responsabilização dos gestores e a instituição escolar com uma posição protagonista, à frente das decisões, assim, a NGP vai se configurando como uma resposta ao desafio de qualificar e tornar mais eficiente os sistemas educativos públicos.

Souza (2016) reflete sobre um modelo de administração escolar extremamente hierarquizado e centralizado na figura do diretor. Este deveria ser uma pessoa muito preparada 
intelectualmente, trazendo em sua bagagem conhecimentos administrativos, pedagógicos e educacionais de forma geral. Deve ser defensor das políticas educacionais mais amplas, pois seu papel dentro da escola, além de dirigir, é de um representante legal do estado. Leão (1945) salienta a ascendência pedagógica da administração escolar, no entanto, observa-se nos objetivos da Administração Escolar a predominância do caráter administrativo (DRABACH, 2011).

Uma hipótese que pode auxiliar a explicar tal postura é a de que, para o autor (Leão), a origem da função do diretor escolar é pedagógica, como de resto é todo o objetivo do seu trabalho, todavia, para buscar tais objetivos, o diretor opera no campo administrativo e de representação política do poder instituído (SOUZA, 2006, p. 30).

Na gestão pedagógica, o diretor deve construir e atuar no coletivo e no cumprimento das diretrizes legais vigentes e das regras, de modo a conviver com todos os segmentos da comunidade escolar. Deve promover a análise do currículo em movimento na escola, sala de aula e estudos que permitam a adaptação do currículo oficial pela equipe escolar, para 0 acompanhamento do seu desenvolvimento nos diferentes níveis, modalidades, etapas, áreas e disciplina de ensino (SÃO PAULO, 2013).

\section{GESTÃO PARTICIPATIVA}

A administração escolar não é realizada pelo esforço de uma única pessoa, mas sim com o esforço de um grupo, em que a última palavra deve ser dada pelo diretor, pessoa que está no topo dessa hierarquia e é aceito como o representante da lei e da ordem, sendo o responsável pelo controle e supervisão das atividades desenvolvidas em uma escola (PARO, 2006).

A participação, em seu sentido pleno, caracteriza-se por uma força de atuação consciente, pela qual os membros de uma unidade social reconhecem e assumem seu poder de exercer influência na determinação da dinâmica dessa unidade, de sua cultura e seus resultados. Esse poder é resultante da competência e vontade de compreender, decidir e agir sobre questões que lhe são afetas, dando à unidade social vigor e direcionamento firme (LÜCK, 2009).

Na esfera da educação, a Gestão Escolar Participativa tem como objetivo incluir toda a comunidade escolar - alunos, professores, funcionários e pais dos estudantes nos processos de tomada de decisão, na programação de objetivos, na implementação de projetos escolares e no auxílio da execução de atividades conjuntas (FOSSÁ, 2020, p. 2). 
$\mathrm{Na}$ gestão escolar existem formas diferenciadas de participação, que dependem do contexto, elas podem ser de presença, de expressão verbal e discussão, de representação política, de tomada de decisão, de engajamento (LÜCK, 2006). Dessa forma, a gestão escolar ganha uma nova percepção, desafia aqueles que estão envolvidos, pois necessitam de abertura para aceitar a opinião dos demais e juntos construírem a escola participativa (RIÇARDO, 2020).

A gestão democrática pode possibilitar a participação da comunidade e acompanhar as ações pedagógicas, tendo influência no Projeto Político Pedagógico (PPP). Favorecendo, portanto, o processo democrático. Com o envolvimento da comunidade escolar nos diálogos propícios ao contexto educacional, refletindo o compromisso e a responsabilidade com os objetivos e metas do Projeto Político Pedagógico (PPP) da escola (PARO, 2007).

Libâneo (2004) destaca o PPP como um importante instrumento, contribuindo para participação de pessoas com responsabilidades e criticidade atuando na escola e na comunidade. O PPP é um documento que auxilia diretamente na elaboração do planejamento de ensino, porém se constitui em um processo elaborado para atender as necessidades da escola como um todo, cada turma possui sua particularidade e cada aluno sua individualidade, por isso o planejamento de ensino é importante, pois consegue envolver o cotidiano do aluno diretamente com o professor e o mesmo é capaz de interagir e colocar em ação planos para atender as reais necessidades de ensino e de aprendizagem (NASCIMENTO, 2019). A complexidade desta tarefa exige interação entre todos os atores, docentes ou não-docentes.

O Projeto Pedagógico demanda a ênfase na construção coletiva. Evidencia-se, assim, 0 diálogo entre a ótica do singular de cada sujeito e também de que o projeto pedagógico tem propósitos institucionais, vale dizer que, conforme Bicudo (2001), há um potencial articulador nesta sinergia, não descuidando da unidade do projeto educativo. Ou como afirma Veiga (2016, p. 61-62): "o projeto é um meio de engajamento coletivo para integrar ações dispersas, criar sinergias no sentido de buscar soluções alternativas para diferentes momentos do trabalho pedagógico-administrativo, desenvolver o sentimento de pertença, mobilizar os protagonistas para a explicitação de objetivos comuns". Nesta ótica o projeto dá o rumo e a direção.

Atentar para esta direção exige a participação de alta intensidade de que fala Santos (2004), em outras palavras, o processo decisório necessita ser descentralizado e coletivo. Supõe outro tanto, acreditar no processo de participação, criando espaços para que ele se efetive. Neste viés, "os sujeitos são chamados a 'participar' na hora da implementação da reforma e não no momento de sua concepção" (SUDBRACK, 2009, p. 148), tal ato não se constitui em participação efetiva, mas um arremedo de participação, fazendo com que a mesma seja 
desacreditada de seu potencial emancipatório. Os espaços de participação têm sido notoriamente exíguos, desencadeando decisões arbitrárias e refratárias à democracia (SUDBRACK, 2009). Consoante ensina Lück (2006, p. 29)

[...] a participação em sentido pleno é caracterizada por mobilização efetiva dos esforços individuais para superar atitudes de acomodação, alienação, marginalidade, comportamentos individualistas e estimular a construção de espírito de equipe.

Com efeito, o sentido da participação exige atuação consciente, poder de influenciar e tomar parte das decisões. É processo dinâmico, em movimento.

\section{CONCLUSÕES}

Conclui-se que, por meio do processo educativo, pode-se configurar a base para a construção de um país mais democrático, uma vez que a adoção de mecanismos de gestão democrática da educação possibilita a construção de práticas e vivências democráticas nas escolas. E, a partir das medidas em que as vivências se materializam no cotidiano escolar, na mesma lógica se constrói o potencial de democratização da sociedade. Contudo, ainda há um longo caminho a percorrer no sentido da expansão de práticas democráticas no interior da escola e dos sistemas educativos.

A gestão democrática, com a participação de alta intensidade contribuirá para tornar a escola um ambiente mais colaborativo para os sujeitos envolvidos. Ainda é grande a necessidade de os gestores e a comunidade tomarem consciência da importância da sua participação para melhorar o processo educacional.

\section{REFERÊNCIAS}

ARANHA, Maria Lúcia de Arruda. História da Educação. São Paulo/SP: Editora Moderna, 1996. ISBN: 9788516015602

ASSMANN, Hugo. Reencantar a Educação. Rio de Janeiro/RJ: Editora Vozes, 2007. ISBN: 9788532620248

BRASIL. Por uma política de valorização dos trabalhadores em educação: em cena, os funcionários de escola. Brasília/DF: Ministério da Educação e Cultura - MEC/SEB, 2004.

BRASIL. Lei Federal N. 9.394/96, de 20 de dezembro de 1996. Estabelece as Diretrizes e Bases da Educação Nacional. Diário Oficial da União (DOU), Seção 1, Brasília/DF, p. 27839, dez. 1996. 
BRASIL. Constituição da República Federativa do Brasil de 1988. Brasilia/DF, out. 1988. Disponível em: <www.planalto.gov.br/ccivil_03/constituicao/constituicaocompilado.htm>. Acesso em: 28 ago. 2015.

BRESSER-PEREIRA, Luiz Carlos. Gestão do setor público: estratégia e estrutura para um novo estado. In: BRESSER-PEREIRA, Luiz Carlos; SPINK, Peter. (Orgs.) Reforma do estado e administração pública gerencial. Rio de Janeiro/RJ: Fundação Getúlio Vargas, 1998. ISBN: 9788522510535

CHIZZOTTI, Antônio. Pesquisa qualitativa em Ciências Humanas e Sociais. Petrópolis/RJ: Editora Vozes, 2006. ISBN: 9788532633903

DRABACH, Nadia Pedrotti. Gestão da educação pública brasileira: uma perspectiva histórica. In: $X$ Congresso Nacional de Educação (EDUCERE), I Seminário Internacional de Representações Sociais, Subjetividade e educação (SIRSSE). Anais: [...], 10, Curitiba/PR, 2011.

FOSSÁ, Marcelo. Você sabe o que é gestão escolar participativa? Blog Sponte, out. 2020. Disponível em: <https://www.sponte.com.br/voce-sabe-o-que-e-gestao-escolar-participativa/>. Acesso em: 09 jun. 2021.

GROSSI, Esther Pillar. Como areia no alicerce: ciclos escolares. São Paulo/SP: Editora Paz e Terra, 2004. ISBN: 9788521907534

GUERRA, Miguel Ángel Santos. La escuela que aprende. Madrid/Espanha: Editora Morata, 2000. ISBN: 9788471124494

HARGREAVES, Andy. 0 ensino na sociedade do conhecimento: educação na era da insegurança. Porto Alegre/RS: Editora Artmed, 2004. ISBN: 9789720348203

LEÃO, Antônio Carneiro. Introdução à Administração Escolar. 2. ed. São Paulo/SP: Companhia Editora Nacional, 1945.

LIBÂNEO, José Carlos. A escola com que sonhamos é aquela que assegura a todos a formação cultural e científica para a vida pessoal, profissional e cidadão. In: COSTA, Marisa (Org.). A escola tem futuro? Rio de Janeiro/RJ: Editora DP\&A, 2004. ISBN: 9788598271439

LÜCK, Heloísa. Dimensões da gestão escolar e suas competências. Curitiba/PR: Editora Positivo, 2009. ISBN: 9788538500278

LÜCK, Heloísa. Gestão participativa na escola. Petrópolis/RJ: Editora Vozes, 2006. ISBN: 9788532655615

MONTEIRO, Vitor Borges; ARRUDA, Elano Ferreira. O impacto da violência urbana nos indicadores de evasão escolar na Região Metropolitana de Fortaleza. In: I Circuito de Debates Acadêmicos. Anais: [...]. 1. Brasília/DF: Instituto de Pesquisa Econômica Aplicada (IPEA), 2011.

NASCIMENTO, Aldivânia Santos do. Planejamento participativo nas aulas de educação física. Revista Educar, São Paulo/SP, v. 18, n. 1, mar. 2019. ISBN: 2447-7931. 
OLIVEIRA, Dalila Andrade. Nova gestão pública e governos democráticos populares: contradições entre a busca da eficiência e a ampliação do direito à educação. Educação \& Sociedade, Campinas/SP, v. 36, n. 132, p. 625-646, jul./set. 2015. DOI: https://doi.org/10.1590/ES0101-73302015152440.

PARO, Vitor Henrique. Administração Escolar: Introdução Critica. São Paulo/SP: Editora Cortez, 2006. ISBN: 9788524919541

PARO, Vitor Henrique. Gestão escolar, democracia e qualidade de ensino. São Paulo/SP: Editora Ática, 2007. 120p. ISBN: 9788584991204

RIBEIRO, Wagner Costa; ZANIRATO, Silvia Helena. Conhecimento tradicional e propriedade intelectual nas organizações multilaterais. Ambiente \& Sociedade, Campinas/SP, v. X, n. 1, p. 39-55, jan./jun. 2007. ISSN: 1414-753X

RIÇARDO, Júlia. Gestão Escolar: espaço para a participação. Brasil Escola, 2020. Disponível em: <https://monografias.brasilescola.uol.com.br/pedagogia/gestao-escolar-espaco-paraparticipacao.htm>. Acesso em: 16 jul. 2020.

RUDDUCK, Jean. Mudando o mundo da sala de aula, compreendendo-o: uma revisão de alguns aspectos da obra de Laurence Stenhouse. Journal of Curriculum and Supervison, Alexandria/Egito, v. 4, n. 1, p. 30-42, 1988. Disponível em:

$<$ http://www.ascd.org/publications/jcs/fall1988/Changing-the-World-of-the-Classroom-byUnderstanding-It@-A-Review-of-Some-Aspects-of-the-Work-of-Lawrence-Stenhouse.aspx>. Acesso em: 30 mar. 2021.

SANTOS, Boaventura de Sousa. A crítica da razão indolente - Contra o desperdício da experiência. São Paulo/SP: Cortez, 2000.

SÃO PAULO. Resolução n. 52, de 14 de agosto de 2013. Dispõe sobre os perfis, competências e habilidades requeridas dos Profissionais da Educação da rede estadual de ensino, os referenciais bibliográficos e de legislação, que fundamentam e orientam a organização de exames, concursos e processos seletivos, e dá providências correlatas. Diário Oficial Poder Executivo, Seção I, v. 123, n. 152, p. 31, São Paulo/SP, 2013.

SOUZA, Ângelo Ricardo de. Perfil da Gestão Escolar no Brasil. 2006, 302f. Tese (Doutorado em Educação). Programa de Pós-Graduação em Educação, Pontifícia Universidade Católica de São Paulo. São Paulo/SP, 2006.

SOUZA, Allan Solano. Responsabilização na Administração da Educação: a política de responsabilidade educacional como engrenagem de controle de resultados. 2016. 315f. Tese (Doutorado em Educação). Programa de Pós-Graduação em Educação, Universidade Federal do Rio Grande do Norte, Natal/RN, 2016.

SOUZA, Allan Solano; CABRAL NETO, Antônio. A nova gestão pública em educação Planejamento estratégico como instrumento de responsabilização. Revista Retratos da Escola, Brasília/DF, v. 11, n. 21, p. 621-640, jul./dez. 2017. ISBN: 1982-131X. 
SUDBRACK, Edite Maria. Rosa dos Ventos: traços da formação docente pós-LDB. Porto Alegre/RS: Editora da UFRGS, 2009.

TREINTA, Fernanda Tavares; et al. Metodologia de pesquisa bibliográfica com a utilização de método multicritério de apoio à decisão. Revista Produção, Niterói/RJ, v. x, n. x, p. 01-13, nov. 2012. ISSN: 1676-1901

VEIGA, IIma Passos Alencastro. Educação Superior: políticas educacionais, currículo e docência. Curitiba/PR: Editora CRV, 2016. 